This item was submitted to Loughborough's Research Repository by the author.

Items in Figshare are protected by copyright, with all rights reserved, unless otherwise indicated.

\title{
Energy economy analysis of the G-Wiz: a two-year case study based on two vehicles
}

PLEASE CITE THE PUBLISHED VERSION

http://dx.doi.org/10.1177/0954407011408369

PUBLISHER

Sage (@ Institution of Mechanical Engineers)

VERSION

AM (Accepted Manuscript)

LICENCE

CC BY-NC-ND 4.0

REPOSITORY RECORD

Chaudhari, Anita, and R.H. Thring. 2011. "Energy Economy Analysis of the G-wiz: A Two-year Case Study Based on Two Vehicles”. figshare. https://hdl.handle.net/2134/9067. 
This item was submitted to Loughborough's Institutional Repository (https://dspace.lboro.ac.uk/) by the author and is made available under the following Creative Commons Licence conditions.

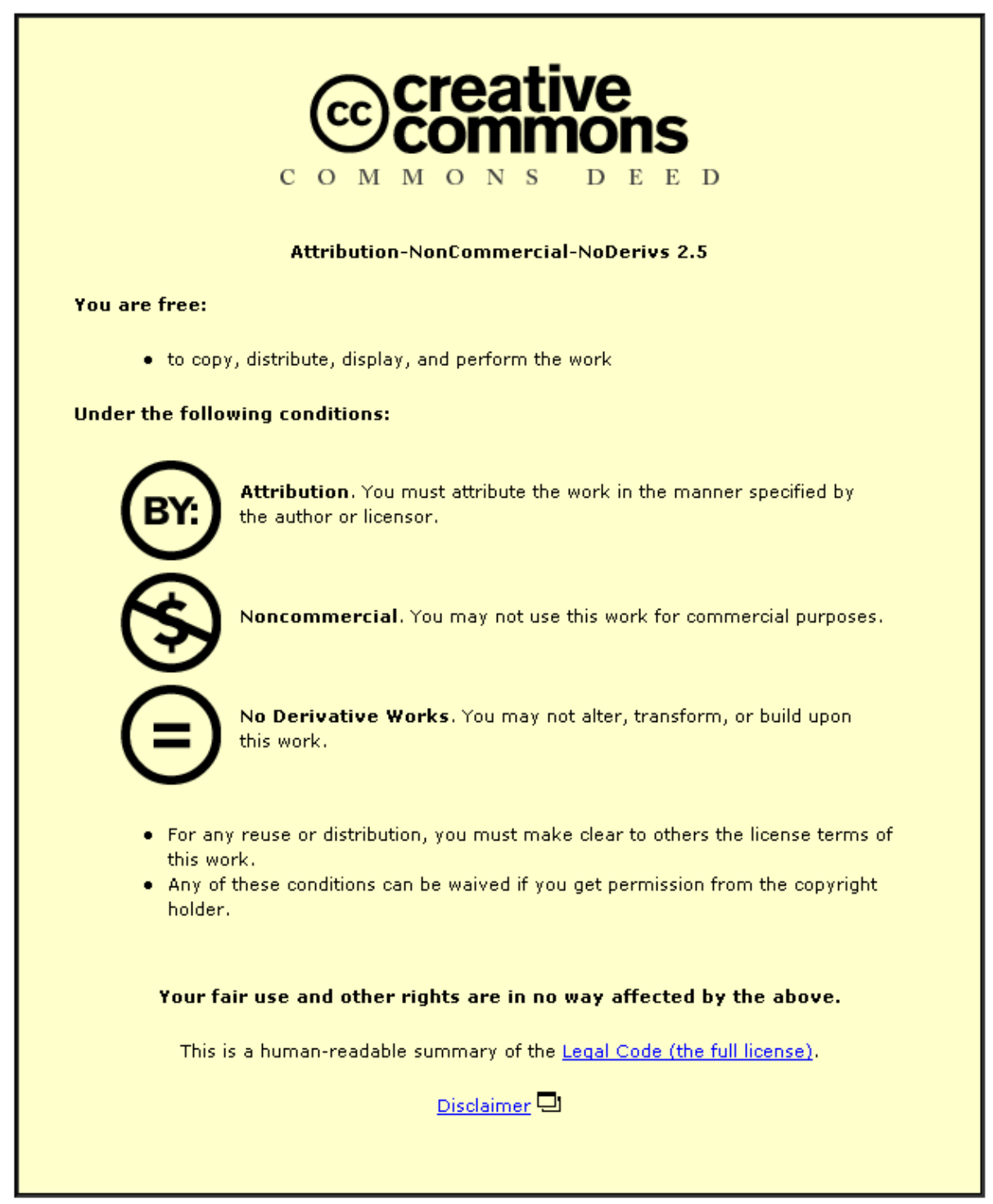

For the full text of this licence, please go to: http://creativecommons.org/licenses/by-nc-nd/2.5/ 


\title{
Energy Economy Analysis of the G-Wiz: A Two year Case Study Based on Two Vehicles
}

Anita R Chaudhari, Rob H Thring, Loughborough University, Loughborough, LE11 $3 T U$

\begin{abstract}
This paper presents the data recorded from two G-Wiz Reva Electric Vehicles (EV) over a period of two years and approximately $8000 \mathrm{~km}$ on each vehicle. The analysis of the vehicle data demonstrated that the range of the vehicle obtained for a certain state-of-charge (SOC) drop was not consistent. The results show that the main factor affecting the available range was irregular vehicle usage. The recharge energy consumption patterns of the vehicle were identified and it was demonstrated that infrequent vehicle usage increased energy consumed by the vehicle. A maximum range of $66.8 \mathrm{~km}$ was achieved when the vehicle was regularly used but this fell to $42.8 \mathrm{~km}$ when it was infrequently used. The energy economy when the vehicle was regularly used was $8.3 \mathrm{~km} / \mathrm{kWh}$. Additionally, the analysis results identify the need to determine discharge rate of the vehicle batteries to determine the precise effects on the available range and energy consumption of the vehicle.
\end{abstract}

Keywords: Electric vehicle, range estimation, usage patterns, energy economy 


\section{Introduction}

There is a strong need to reduce carbon dioxide $\left(\mathrm{CO}_{2}\right)$ emissions due to their environmental impact and $\mathrm{CO}_{2}$ emissions from the transport sector account for $20 \%$ of UK's total $\mathrm{CO}_{2}$ emissions [1]. The low carbon initiatives launched by the UK government have pushed vehicle manufacturers and consumers towards hybrids, electric vehicles (EVs), and ultra-low emission, petroleum-fuelled vehicles. In 2008, the efforts of the manufacturers resulted in the steepest rate of decline per year of fleet average $\mathrm{CO}_{2}$ emissions since 1997 from $164.9 \mathrm{~g} / \mathrm{km}$ in 2007 to $158 \mathrm{~g} / \mathrm{km}$ in 2008 for average new cars in the UK [1].

The King report [2] has discussed the need to decarbonise vehicles through the use of batteries, hydrogen and some biofuels. The report also predicts the integration of road transport and power generation in future and recommends facilitating efficient EV use and taking steps to encourage consumers to buy low carbon vehicles.

Battery electric vehicles (BEV) have the potential to significantly reduce the $\mathrm{CO}_{2}$ emissions as compared to similar IC engine-based vehicles, depending on the source of electricity used for charging the BEVs [3]. For power generation mixes with low $\mathrm{CO}_{2}$ intensity $\mathrm{BEVs}$ can potentially reduce $\mathrm{CO}_{2}$ emissions, but for high $\mathrm{CO}_{2}$ intensity power generation BEVs can have higher $\mathrm{CO}_{2}$ emissions than similar IC engine-based vehicles [3].

The G-Wiz produces $62.6 \mathrm{~g}$ of $\mathrm{CO}_{2} / \mathrm{km}$ when charged by electricity from a power station based on UK's Primary Fuel Mix [4]. In comparison the Smart fortwo coupe petrol automatic version produces $118 \mathrm{~g}$ of $\mathrm{CO}_{2} / \mathrm{km}$ as tailpipe emissions [5]. 
As a result, electric vehicles such as the G-Wiz Reva already exist in the UK vehicle fleet. The proportion of vehicles with alternative technology (Hybrid and electric vehicles and those fuelled by biofuels) was only $0.7 \%$ in 2008 [1]. The limited number of electric vehicles is due to lack of vehicle charging infrastructure, long charging periods, high costs and limited range of the vehicle as compared to existing petrol or diesel vehicles. The 'range' of an EV is defined here as the distance the vehicle will travel during a journey or journeys, starting from $100 \%$ state-of-charge (SOC) $\mathrm{SOC}_{\max }$ and ending at the minimum acceptable level of charge for the type of battery $\left(\mathrm{SOC}_{\min }=20 \%\right.$ for the G-Wiz). These factors contribute to a reduced practicality for the end user, who traditionally is accustomed to vehicle ranges of 500$800 \mathrm{~km}$.

Walsh et al [6] have analysed the vehicle performance of a Smart ed (electric drive) with real world driving data and laboratory tests. The vehicle is powered by a sodiumnickel-chloride battery. The authors have analysed the performance of the vehicle with respect to the range of the vehicle, charge-discharge characteristics of the battery, energy economy and equivalent $\mathrm{CO}_{2}$ and cost analysis. This work [6] indicates that the range of the Smart ed was consistent during laboratory driving cycles but the real world driving resulted in differing range. This work also investigates range variation between different drivers. Due to high operating temperature of the Smart ed batteries, high utilisation of the vehicle resulted in lower $\mathrm{CO} 2$ emissions [6]. Research conducted by Alessandrini et al [7] includes real driving data acquisition with the electric Citroen Saxo. The main focus of this work was to highlight the differences in the behaviour of an electric car and conventional car and develop a drive cycle suited for electric vehicles in Rome. Literature on EV performance analysis from real world driving is very limited, hence there is a strong 
need for analysing EVs with various battery types, to identify the limitations in vehicle performance, and any possible areas of improvement.

The report produced by Aston University - 'CABLED project for ultra-low carbon vehicles trial' includes data analysis of usage patterns of electric vehicle users [8]. The report evaluates the daily mileage, journey distance, journey duration, average number of journeys each day, average speed, ambient temperature, energy consumption, charging time and duration for the whole vehicle fleet. The results are indicative of user behaviour which can be useful for infrastructure development for large scale EV deployment. Similarly the report published by Cenex - 'the smart move trial' [9] aims to accelerate the adoption of electric vehicle, study integration of EVs into fleets and study efficiency and performance of these vehicles. The results indicate the effect of factors such as ambient temperature and regenerative braking on the range. The journey lengths and altered driving behaviour at low SOCs was observed. Both these reports have a focus on user perception and acceptance of EVs and their wider impact on available infrastructure.

As compared to the two reports on 'the smart move trial' and 'CABLED project for ultra-low carbon vehicles trial', this paper focuses on the effects of the frequency of vehicle usage on the range and energy consumption.

Ceraolo et al [10] have discussed an algorithm based on a simulated battery model, to determine the residual range of an $\mathrm{EV}$, considering effects of past history on charge, temperature and present driving conditions. The range estimation model highlights the effects on the range due to varying discharge rate of the vehicle batteries during driving. The effectiveness of the algorithm was verified experimentally. 
In contrast to the work described by Ceraolo et al [10], this paper approaches the issue of residual range determination by analysing experimentally obtained data, with a view to develop a model in future. This paper presents an analysis of range of the two G-Wiz electric vehicles under on road driving conditions, and also analyses the recharge energy consumption patterns of the vehicle from experimentally obtained data.

The characteristics of lead-acid batteries such as self discharge and sulphation, effect of high discharge rates, water depletion have been discussed by authors such as Leitman et al [11] and Rand et al [12]. The discharging process in lead acid batteries involves a reaction between lead oxide and sulphuric acid to form lead sulphate. Peukert's law for lead acid batteries describes the capacity of the battery in terms of the discharge rate [12]. Ambient temperature has a significant effect on lead acid battery performance, which the Peukert coefficient does not take into account [13]. The ways in which these battery characteristics affect the vehicle behaviour have been discussed in this paper.

The main objectives of this paper are:

- To characterise the vehicle by determining the factors that affect vehicle range,

- To predict the extent to which the vehicle range is affected by the usage patterns

- To determine the energy consumption patterns when the vehicle is connected to the power supply.

- To determine the energy economy and identify the effect of usage patterns on recharge energy consumption of the EV. 


\section{Problem statement:}

Loughborough University owns two G-Wiz Reva vehicles. The vehicle's specifications are given in Table 1.

In this table, one can see that most of the features on the two vehicles are similar except the maximum speed of the vehicle.

The work involved analysis of actual on the road driving data accumulated over two years, by two drivers with the two vehicles. One driver drove the vehicle for shorter distances, while the other did a return journey of $29 \mathrm{~km}$ each way on a regular basis. Hence, the data collected represents a snapshot of real world performance. Data recorded included SOC, distance travelled, energy supplied to vehicles and information regarding the use of in-vehicle accessories. The SOC of the battery pack is recorded from information displayed by the vehicle's Energy Management System (EMS). The data gives valuable information regarding usage patterns and their effects on the recharge energy consumption and the range of the vehicle.

While the data recorded by testing the vehicle on the chassis dynamometer under lab conditions would be better controlled and probably have less scatter, the data in this paper is taken from driving on public roads and therefore is more representative of real world conditions.

Certain unpredictability with the range achieved by the vehicle was noted by the drivers. Similarly the recharge energy consumption of the vehicle also had a wide variation for a fixed distance travelled. This paper addresses this perceived unpredictability with the vehicle range and examines the conditions under which the recharge energy consumption is above average. 


\section{Methodology}

Data were recorded for both vehicles while being driven on public roads over a period of two years and included the distance travelled, SOC of the vehicle before and after the journey, date of journey, use of any accessories, frequency of watering, equalisation of batteries, the energy supplied to the vehicle and the driver's name. These logs were manually recorded by the drivers after each journey.

The data are analysed, and sorted to classify them into usage patterns and used to determine the behaviour of the battery, the vehicle range and the energy supplied to the vehicle based on these classifications.

The data includes journeys which were conducted on a full charge, and the vehicle was connected to the power supply for recharging after the journey. The data suggested an effect of vehicle usage on the range as well as the recharge energy. In order to quantify this effect a usage factor was defined (see section 4.1.3). The usage factor is calculated on the basis of the manufacturer's specifications for maximum depth of discharge (DOD) allowable for the vehicle batteries.

The effect of infrequent usage versus regular usage, and the use of accessories on range and recharge energy were evaluated. Charging and discharging characteristics of the vehicle were observed and data were recorded for charging and discharging characteristics of the vehicle battery using the "BMS Monitor" software (version 3) [14]. The EMS of the vehicle sends data every 2 seconds through a serial port. The data includes individual battery voltages, current, speed of the vehicle, fault data, SOC, ampere-hours, motor and controller temperature. This data was recorded by the BMS Monitor software using a laptop. 
The effects of the equalisation process and watering on the vehicle performance were noted. A typical method for charge equalisation for series-connected cells in batteries involves overcharging [11]. This technique is used to equalize battery pack voltages in these vehicles and the process involves consumption of a significant amount of water (about 3 litres) and energy (about $2 \mathrm{kWh}$ more than that required for a full charge).

\section{Results}

An analysis of the range and effects of various parameters on the range are discussed in this section. The energy consumed by the vehicle to recharge and maintain the charge over a period of time was observed. The relationship between the energy consumed by the vehicle and the DOD of the journey along with the period of time the vehicle was left for charging is established based on experimental data.

\subsection{Effect on Range}

\subsubsection{Comparison of the range of the two vehicles}

In order to determine the estimated range of the vehicle, the actual distance $(x \mathrm{~km})$ travelled from a full charge $\left(\mathrm{SOC}_{\max }=100 \%\right)$ to $\mathrm{SOC}_{\mathrm{end}}$ at end of the journey, was extrapolated to determine the distance the vehicle would travel for a maximum permissible SOC drop $\left(\mathrm{SOC}_{\min }=20 \%\right)$, as shown in Equation 1. Figure 1 shows the estimated range of each vehicle with respect to the SOC at the start along with a linear regression fit of the data points for each vehicle.

Estimated Range $=\frac{\mathrm{x} \times\left(\mathrm{SOC}_{\max }-\mathrm{SOC}_{\min }\right)}{\left(\mathrm{SOC}_{\text {start }}-\mathrm{SOC}_{\mathrm{end}}\right)}$ 
The vehicles have identical batteries but the usage pattern for each vehicle has been different. Vehicle 1 was regularly used for shorter journeys (average journey length $16 \mathrm{~km}$ ) as compared to vehicle 2 while the latter was used mostly for the same route (of about $29 \mathrm{~km}$ ) on a regular basis.

Vehicle 2 has slightly higher maximum speed as compared to the vehicle 1 and allows slightly faster acceleration. The poorer range of vehicle 2 can be explained due to higher discharge rates due to higher maximum achievable speed of the vehicle. This shows the dependence of the range of the vehicle on the speed profile during the journey which corresponds to discharge rate of the batteries.

Discharging a lead-acid battery causes an increase in the cell resistance of the battery due to lead sulphate formation and depletion of the sulphuric acid [12]. Lead sulphate deposits in the active sites cause a pore-blocking effect, which is aggravated at high discharge rates, (e.g., acceleration of an EV) and reduces the battery capacity and available range of the vehicle [12].

The scatter observed in the estimated range for a particular state of charge is due to different speed profiles for each journey and other effects which are further discussed.

\subsubsection{Cumulative Effect of usage patterns on vehicle range}

Figure 2 shows the cumulative effects of the vehicle usage pattern on the vehicle range.

The figure compares the vehicle range as expected according to the manufacturer's specifications with the actual driving performance. The intercept at $80 \%$ SOC drop 
indicates the range achievable for the journeys. The journeys in the above plot are classified based on the vehicle usage as follows:

1. Data points for distance travelled and the corresponding SOC drop for journeys when the vehicle was used daily for two or more consecutive days. (A1)

2. Data points for distance travelled and the corresponding SOC drop for journeys when the vehicle was not used for two or more days (i.e., vehicle storage period was greater than two days) (A2)

3. Data points for distance travelled and the corresponding SOC drop for journeys when the vehicle was used with accessories such as lights, wipers, heater, etc. (A3)

Regular usage of the vehicle is shown by the circular markers and a linear regression fit to the data is shown by the dotted line. This data shows that the vehicle range achievable for the classifications A1, A2 and A3 is $57.7 \mathrm{~km}, 42.7 \mathrm{~km}$ and $51.6 \mathrm{~km}$ respectively. The trend lines indicate that the vehicle range achieved is lower than that specified by the manufacturer. $(77.2 \mathrm{~km})$

The use of accessories results in reduction of vehicle range, since the accessories also draw power from the battery pack and act as added loads. The difference in the achievable range from classifications $\mathrm{A} 1$ and $\mathrm{A} 2$ indicate the effect of long storage periods resulting in reduced range. To further evaluate this effect of usage of the vehicle, a 'usage factor' (UF) is described in the following sections.

Figure 3 shows a number of data-sets which show the extent of reduction in DOD/km after the vehicle has been unused for at least one day prior to Day 1 . The data sets 
selected represent journeys conducted every day (for $3-7$ days) after a period of nonusage. The first journey (Day 1) after the period of non-usage shows high values of depth of discharge (up to $1.8 \mathrm{DOD} / \mathrm{km}$ ) for the distance travelled over the journey. This journey results in a much lower calculated range (using Eqn. 1) than that specified by the manufacturer (53 $\mathrm{km}$ or less).

A marked improvement is observed on Day 2 with DOD/km values between 1.2 1.45 which equates to a calculated range of $55.2-66.7 \mathrm{~km}$. On Day 2, the range performance is improved significantly as compared to Day 1 (lower DOD/km). As indicated by the mean value trend line, on the following days, a relatively small variation is observed in the DOD/km eventually achieving a steady value. The maximum estimated range achieved by the vehicle during the two years was $66.8 \mathrm{~km}$, so the figure shows that most of the recovery occurred after Day 1. From Figure 3 it can be concluded that even a single day of non-usage can diminish the achievable range of the vehicle and that the most of the recovery in the range performance is visible after a single journey.

For the journey on Day 4, it appears that due to daily usage on Days 1, 2 and 3, the range variation is small as compared to that after a period of non-usage. Hence the extent of usage on the day before the journey strongly impacts the achievable range for the journey.

\subsubsection{Usage Factor}

As seen in Figure 2, when the vehicle was not used for a few days, the range of the vehicle fell to $55.3 \%$ of that specified by the manufacturer. This is a significant reduction and in order to quantify it, there is a need for a usage factor. This factor will 
determine the extent of vehicle usage prior to a journey over a specific period of time and allows examining its effects on the vehicle range.

Initially a usage factor $\left(\mathrm{UF}_{1}\right)$ was developed such that it evaluated the extent of vehicle usage for one day before a journey was to be conducted. For example, for a vehicle to be used on day1, if the DOD of the journey conducted the day before day1 is $\mathrm{DOD}_{-1}=60 \%$, and the maximum possible DOD for the battery type is $\mathrm{DOD}_{\max }=80 \%$, then usage factor is $\mathrm{UF}_{1}=60 / 80=0.75$.

Figure 4 shows a plot of the DOD per distance travelled against $\mathrm{UF}_{1}$, for all the journeys conducted by vehicle 1 . The trend line shows the drop in DOD/km as the usage factor increases. Based on the trend line, for a usage factor of 1 , the DOD/km is 1.349, which translates to a maximum vehicle range of $59.3 \mathrm{~km}$. The plot demonstrates the fact that increase in vehicle usage results in increase in the vehicle range. The importance of usage of the vehicle on the day before a journey is highlighted from this plot.

The main shortcoming of this plot is the large number of points on the Y-axis, when usage factor is zero. A zero usage factor indicates that the vehicle was unused for at least one day, but gives no indication if the vehicle was unused for a longer period and its subsequent effects on the range.

Figure 4 highlights the deficiency in the usage factor $U_{1}$. In order to address the effect of usage over a period of time on the vehicle range, an improved usage factor 
was proposed. This usage factor was calculated based on the extent of cycling, i.e. DOD of the batteries in the previous few journeys.

The usage factor is defined in Equation 2.

$$
U F_{n}=\frac{\sum_{x=1}^{n}\left(D O D_{x} \times a_{x}\right)}{D O D_{\max } \times \sum_{x=1}^{n} a_{x}}
$$

Where $n$ is the number of days considered for UF calculation

$x$ indicates the day number

$a$ is the weighting coefficient

An example of usage factor considering $n=4$ days is given below, i.e., for calculating the usage factor for a certain day ' $y$ ', the DOD over the 4 days prior to day ' $y$ ' is considered resulting in the following equation.

$$
\mathrm{UF}_{4}=\frac{\mathrm{a}_{1} \times \mathrm{DOD}_{\text {day } 1}+\mathrm{a}_{2} \times \mathrm{DOD}_{\text {day } 2}+\mathrm{a}_{3} \times \mathrm{DOD}_{\text {day } 3}+\mathrm{a}_{4} \times \mathrm{DOD}_{\text {day } 4}}{80 \times\left(\mathrm{a}_{1}+\mathrm{a}_{2}+\mathrm{a}_{3}+\mathrm{a}_{4}\right)} \quad \ldots . \text { Equation } 3
$$

As the trend lines in Figure 3 and 4 show that the usage of the vehicle on the day before the journey has an impact on the range of the vehicle, the coefficients are chosen such that at least $50 \%$ of the sum of the coefficients is given to the previous day $\left(a_{1}\right)$. The values of the coefficients $a_{1}, a_{2}, a_{3}, a_{4}$, must be in a decreasing order to allow the day before the journey to be given the maximum weight. The coefficients $a_{2}, a 3$ and $a_{4}$ have been given values of half, quarter and one-eighth of the value of $a_{1}$ respectively. 
As an example, using the data in Table 2, and Equation 3, the usage factor $\mathrm{UF}_{4}$ for $07 / 11 / 07$ is calculated as 0.3333 .

A number of different combinations of coefficients with various values were examined for the usage factor calculation. It was observed that it did not make a significant difference to the trend lines or values of the usage factors. But the selected coefficients (as in Table 2) indicated that when $\mathrm{UF}_{4}=1$, the DOD/km was 1.198 . This corresponds to $66.77 \mathrm{~km}$ range which is the closest match to the value of the maximum range that was achieved by the vehicles during the two years.

Similarly usage factors over 3,4,5,6 and 15 days before day ' $y$ ' were calculated to determine the most suitable usage factor for the analysis. The DOD per distance travelled for the data sets were plotted against the usage factors $\mathrm{UF}_{3}, \mathrm{UF}_{4}, \mathrm{UF}_{5}, \mathrm{UF}_{6}$ and $\mathrm{UF}_{15}$ and a curve fit was obtained for each. The quality of fit for these curves is given in Table 3, where SSE is the sum of squared errors, RMSE is the root mean squared error and $\mathrm{R}^{2}$ is the $\mathrm{R}$-squared value. The best fits were obtained for $\mathrm{UF}_{3}$ and $\mathrm{UF}_{4}$ after which the quality of fit began to decline. Hence it was considered reasonable to select $\mathrm{UF}_{4}$ for all further analysis to allow examining usage over four days prior to the journey. $\mathrm{UF}_{4}$ will be simply termed as 'usage factor' or 'UF' for the following sections of the paper.

\subsubsection{Effect of usage on vehicle range}

Figure 5 shows the DOD per distance travelled for the usage factor calculated over a period of four days as described above. Due to inaccuracies in recording the SOC difference for short journeys, all journeys less than $8 \mathrm{~km}$ have been ignored for the purpose of this analysis. These journeys less than $8 \mathrm{~km}$ constituted only $8.4 \%$ of the 
total mileage covered by the vehicle. The data points enclosed in the ellipse indicate the journeys that were shorter, with distances travelled ranging from 9-16 km. This may indicate that the DOD/km is greater for very short journeys if the usage factor is low. The main difference observed between Figure 4 and Figure 5 is that the intercept made by the curve when the usage factor is one in Figure 5, has a more realistic value of maximum predicted range of $66 \mathrm{~km}$ as compared to that obtained in Figure 4 (59.3 $\mathrm{km})$. A decreasing DOD/km is observed as the usage factor increases, demonstrating the improvement in vehicle range as usage increases.

The observed scatter in the plot may be attributed to the other known factors that affect the vehicle range such as driving style, inclination of road, ambient temperature, and use of accessories or additional passengers in the vehicle.

Figure 6 illustrates the effects of usage on the calculated range of the vehicle. The calculated range of the vehicle is significantly lower than expected when the usage factor is low. When the usage factor is one, the curve shows the maximum achievable range of the vehicle is $69 \mathrm{~km}$.

This method of range calculation only considers the DOD and the corresponding distance travelled. The usage of accessories or additional passengers would act as additional load and would affect the vehicle range. Similarly other conditions known to affect range (such as driving style, ambient temperature, drive cycle and road gradients) have not been considered and can possibly account for the scatter observed in Figure 6. One can conclude from Figure 6, that the usage of the vehicle has a significant impact on the range, but there are other factors which also affect range and need further investigations. This warrants a new method of range calculation which will include all the factors that affect the vehicle performance. 
We can infer from the figures that the range of the vehicle is affected by:

- Use of accessories (Figure 2)

- Regularity of vehicle usage (Figure 3 to Figure 6)

\subsection{Energy Consumption}

The energy consumed by the vehicle batteries for a full charge after journeys was recorded. This energy consumption gives an indication of the running cost of the vehicles. Conventional fossil fuel vehicles consume fuel only when used, but electric vehicles, when connected to the power supply, consume energy to maintain battery SOC over the period when the vehicle is not used. The G-Wiz vehicle is also equipped with a battery heater which draws power from the power supply when connected and in a cold ambient temperature. Hence, it is important to evaluate this factor in the overall energy consumption of the vehicle. If the G-Wiz is disconnected from the power supply for a long period of time, the batteries can be permanently damaged.

Figure 7 illustrates the dependence of the energy consumed for each journey on the usage factor of the vehicle.

The curve fit shows a sharp decrease in energy consumed per $\mathrm{km}$ as the usage factor increases from 0 to 0.4 . As the usage factor increases from 0.4 onwards the drop in the energy consumed per $\mathrm{km}$ is more gradual. When the usage factor is 1 , the energy consumed per $\mathrm{km}$ is $0.12 \mathrm{kWh} / \mathrm{km}$ (resulting in an energy economy of $8.3 \mathrm{~km} / \mathrm{kWh}$ )

Data recorded indicated that when the vehicle was fully charged and connected to the power supply, a small, but constant amount of power (either $66 \mathrm{~W}$ or $188 \mathrm{~W}$ ) was 
drawn from the supply. It was particularly observed that this power drawn was $188 \mathrm{~W}$ when the temperature was less than $5^{\circ} \mathrm{C}$ due to the vehicle's battery heater system. Additionally, the vehicle charging system includes a provision for trickle charging which is activated every 24 hours after the vehicle is connected to the power supply. During the trickle charging cycle, charge is provided for a period of 15 minutes in order to maintain the battery SOC at $100 \%$. The charging current provided during this trickle charging cycle is regulated by the vehicle's energy management system (EMS) according to the SOC levels.

From Figure 7 and using Equation 3, a usage factor of zero indicates the vehicle storage period was at least four days and as a result additional energy was consumed over that duration to maintain the battery temperature and to maintain the SOC at $100 \%$. As the usage factor increases, i.e., the storage period of the vehicle decreases, the energy consumed for battery heating and maintaining SOC decreases.

The recharge energy is the sum of the energy supplied to fully charge the vehicles, energy consumed by accessories, battery heater system, trickle charging system and the energy lost in the charger. At a usage factor of one, the recharge energy is the sum of only the energy consumed for charging the batteries and maintaining the battery temperature in case of a cold ambient.

A number of the journeys conducted by the vehicle included those driven over the same route for a distance of $29 \mathrm{~km}$; the data for these journeys is shown in Figure 8. This plot illustrates the varying amount of energy consumed for the journeys though the distance travelled and the route followed were the same. The figure also implies that the DOD for the journeys was different even though the distance travelled was 
the same. The energy consumed by the vehicle is dependent on the DOD of the journey compared to the actual distance travelled by the vehicle. This also implies that the DOD of the batteries is not directly proportional to the distance travelled, which reinforces the need to determine the precise range of the vehicle.

Figure 8 also shows high recharge energy per distance travelled for low usage factors, due to additional energy required for battery heating and SOC maintenance over the storage period. One can note here that for a usage factor of 0.5 onwards, the energy consumed per distance travelled remains fairly constant and achieves a value of 0.16 $\mathrm{kWh} / \mathrm{km}$ (resulting in an energy economy of $6.25 \mathrm{~km} / \mathrm{kWh}$ ) when the usage factor is 1.

The points shown in Figure 8 in the ellipse indicate that a higher amount of energy was consumed due to the fact that the vehicle battery pack was equalising.

It was particularly noted that parasitic effects such as the trickle charge cycle consumed an average of $0.2 \mathrm{kWh}$ every day, while the battery heating required 66 to $188 \mathrm{~W}$ of power at any instant. When the vehicle was not used for a number of days, the energy consumed by the trickle charging cycling showed a gradual increase between 0.01 to $0.03 \mathrm{kWh}$ each day.

As discussed above, the energy supplied to the vehicle also depends on the ambient temperature, which may explain the deviation of points from the trend line. The points above the trend line indicate high recharge energy consumption. Hence, it can be concluded from the results presented above, that the energy supplied to the vehicle is a function of:

- Depth of Discharge 
- Usage factor

- Ambient temperature

The energy supplied to the vehicle is also dependent on the charger and inverter efficiency which will be studied as future work.

It is important to be clear about the distinction between trickle charge, battery heating and loss in range due to non-use.

1. Trickle charge consumes energy, the amount depending on how long the vehicle is left unused, and as a result increases the energy consumed per kilometre when that energy is measured at the vehicle plug in point, as opposed to measurement at the vehicle wheels.

2. Battery heating also consumes energy, the amount depending on the ambient temperature, how long the vehicle is left unused, and similarly increases the energy consumed per kilometre when that energy is measured at the vehicle plug in point.

3. The loss in range due to non-use of the vehicle is something quite different. It appears to be due to a loss in battery capacity, so that the 200 Ah batteries are effectively no longer $200 \mathrm{Ah}$, but somewhat less than that.

Parasitic losses due to trickle charge and the battery heater were not directly addressed in this paper because the important parameter from the point of view of vehicle $\mathrm{CO}_{2}$ emissions is the $\mathrm{km} / \mathrm{kWh}$, which is a key focus of this paper. To properly understand the third effect above is best done in the laboratory and will be subject of future work. This loss in battery capacity seems also to be associated with loss in battery efficiency, but again that is best measured in the laboratory and will be the 
subject of future work. These losses in battery capacity and efficiency result in reduced range of the vehicle, documented in this paper, and increased energy consumed per kilometre, over and above the increases due to trickle charging and battery heating, also documented in this paper.

The data in Figure 7 are presented in terms of $\mathrm{kWh} / \mathrm{km}$, but can be recalculated in terms of $\mathrm{gCO}_{2} / \mathrm{km}$ if the grid mix of electricity generation is known. Assuming that the vehicle is charged using power with the average grid mix in the UK, which results in $\mathrm{CO}_{2}$ emissions of $545 \mathrm{gCO}_{2} / \mathrm{kWh}$ [15], the result is shown in Figure 9. Comparison with published data for passenger cars, for example the petrol Smart car figure is $118 \mathrm{gCO}_{2} / \mathrm{km}$ [5], indicates that the $\mathrm{CO}_{2}$ emissions of the G-Wiz are very good if the usage factor is high, but not good if the usage factor is below 0.2.

\section{Conclusions and Recommendations}

A maximum range of $66.8 \mathrm{~km}$ was achieved when the vehicle was regularly used but this fell to $42.8 \mathrm{~km}$ when it was infrequently used. A usage factor was developed to enumerate the extent of vehicle use over a specific period prior to a journey. The data from the vehicle indicates that the average usage factor for the vehicle was 0.63 with an average range of $52.7 \mathrm{~km}$. The usage on the day prior to a journey has the maximum impact on the vehicle range with the earlier days having a decreasing effect. At low usage factors the following effects were observed:

- High values of DOD/km (up to $3.5 \mathrm{DOD} / \mathrm{km}$ ) 
- Low vehicle predicted range $(22.8 \mathrm{~km})$

- High values of $\mathrm{kWh} / \mathrm{km}$ and energy economy as low as $1.05 \mathrm{~km} / \mathrm{kWh}$.

Non usage of the vehicle for one or more days results in a diminished range. A single journey after this period of non-usage is sufficient to recover most of the diminished range of the vehicle.

Increasing usage showed a drop in the DOD/km, and increase in predicted vehicle range and reduced recharge energy consumption. The usage of the vehicle has a significant impact on the vehicle range, but other factors (such as driving style, ambient temperature, drive cycle and road gradients) also affect the range and need further investigations.

Energy supplied to fully charge the vehicle is dependent mainly on the DOD of the journey, ambient temperature and the usage factor. The data implies that the energy required for charging the vehicle is more dependent on the DOD of the journey than the distance travelled by the vehicle. Analysis of recharge energy consumption patterns of the vehicle indicates the following:

- For low usage factors up to 0.4 , the energy economy is up to $5 \mathrm{~km} / \mathrm{kWh}$ and the recharge energy consumption of the vehicle shows an exponential drop as the usage factor increases.

- As the usage factor increases above 0.5 , the energy economy is a maximum of $8.3 \mathrm{~km} / \mathrm{kWh}$ and the recharge energy consumption of the vehicle shows a gradual decrease as the usage factor increases.

The $\mathrm{CO}_{2}$ emissions of the G-Wiz are as low as $65.7 \mathrm{gCO}_{2} / \mathrm{km}$ if the usage factor is one, but are very high if the usage factor is lower than 0.2 . The frequency of usage of 
the electric vehicle is a very important consideration to determine the carbon dioxide emissions.

The methodology followed in this paper for energy economy and range analysis is with the help of the usage factor and it is recommended that this may be used for other electric vehicles. The effect of the usage factor on vehicle range and energy economy will vary from one battery type to another.

The data collected was not sufficient to draw conclusions regarding the precise effects of ambient temperature on the vehicle range or energy consumption. The detailed effects of ambient temperature and driving profile on the vehicle range have not been included in this paper and will be examined as future work. Vehicle battery discharge rate at constant speeds and during drive cycles will be investigated in future work. It is recommended that further data be collected over a wider range of journey types and drivers. This paper supports the need for the development of a model predicting the depletion in the range and energy required to fully charge and maintain charge of the vehicle due to usage patterns.

\section{Acknowledgements}

The authors would like to acknowledge the donation of one of the electric vehicles by Reva Electric Car Company. 


\section{List of captions}

Figure 1 - Comparison of the two G-Wiz Reva vehicles

Figure 2 - Distance travelled versus SOC drop of the vehicle based on usage pattern

Figure 3 - Reduction in the depth of discharge per unit distance travelled

Figure 4 - Effect of UF1 on DOD/km

Figure 5 - Effect of Usage factor on DOD/km

Figure 6 - Effect of Usage Factor on the Calculated Range

Figure 7 - Effect of usage factor on recharge energy of vehicle

Figure 8 - Effect of usage factor on recharge energy of vehicle for journeys of $29 \mathrm{~km}$

Figure 9 - Usage factor and $\mathrm{CO}_{2}$ emissions of the G-Wiz EV 


\section{Tables}

Table 1 - Vehicle specifications

Table 2 - Example for Usage factor calculation

Table 3-Quality of fit for various usage factors 


\section{References}

[1] "SMMT New Car CO2 Report," The Society of Motor Manufacturers and Traders, 2009.

[2] J. King, "The King Review of low-carbon cars. Part II - Recommendations for action," Crown copyright, 2008.

[3] R. T. Doucette and M. D. McCulloch, "Modeling the CO2 emissions from battery electric vehicles given the power generation mixes of different countries," Energy Policy, vol. 39, pp. 803-811

[4] "G-Wiz technical specifications," http://www.goingreen.co.uk/store/content/gwiz_techspec/

[5] "SMMT CO2 Emissions Data," http://www.smmtco2.co.uk/co2search2.asp

[6] C. Walsh and C. Bingham, "Electric drive vehicle deployment in the UK," presented at EVS24 International Battery, Hybrid and Fuel Cell Electric Vehicle Symposium, Stavanger, Norway, 2009.

[7] A. Alessandrini and F. Orecchini, "A driving cycle for electrically-driven vehicles in Rome," Proceedings of the Institution of Mechanical Engineers, Part D: Journal of Automobile Engineering, vol. 217, pp. 781-789, 2003.

[8] "Data Analysis Report of ultra-low carbon vehicles from the CABLED trial," Aston University, Birmingham March 2010.

[9] S. Carroll, "the smart move trial: description and initial results," Centre of excellent for low carbon and fuel cell technologies (Cenex) 2010.

[10] M. Ceraolo and G. Pede, "Techniques for estimating the residual range of an electric vehicle," Vehicular Technology, IEEE Transactions on, vol. 50, pp. 109-115, 2001.

[11]S. Leitman and B. Brant, Build your own electric vehicle.: McGraw-Hill, 2009.

[12]D. A. J. Rand, R. Woods, and R. M. Dell., Batteries for electric vehicles: Research Studies Press Ltd, 1997. 
[13]D. Doerffel and S. A. Sharkh, "A critical review of using the Peukert equation for determining the remaining capacity of lead-acid and lithium-ion batteries," Journal of Power Sources, vol. 155, pp. 395-400, 2006

[14] "BMS Monitor," http://www.bmsmonitor.com/

[15] "Carbon Trust Standard Carbon Footprint Spreadsheet," http://www.carbontruststandard.com/DocumentDownload?id=015200000014LkH. 


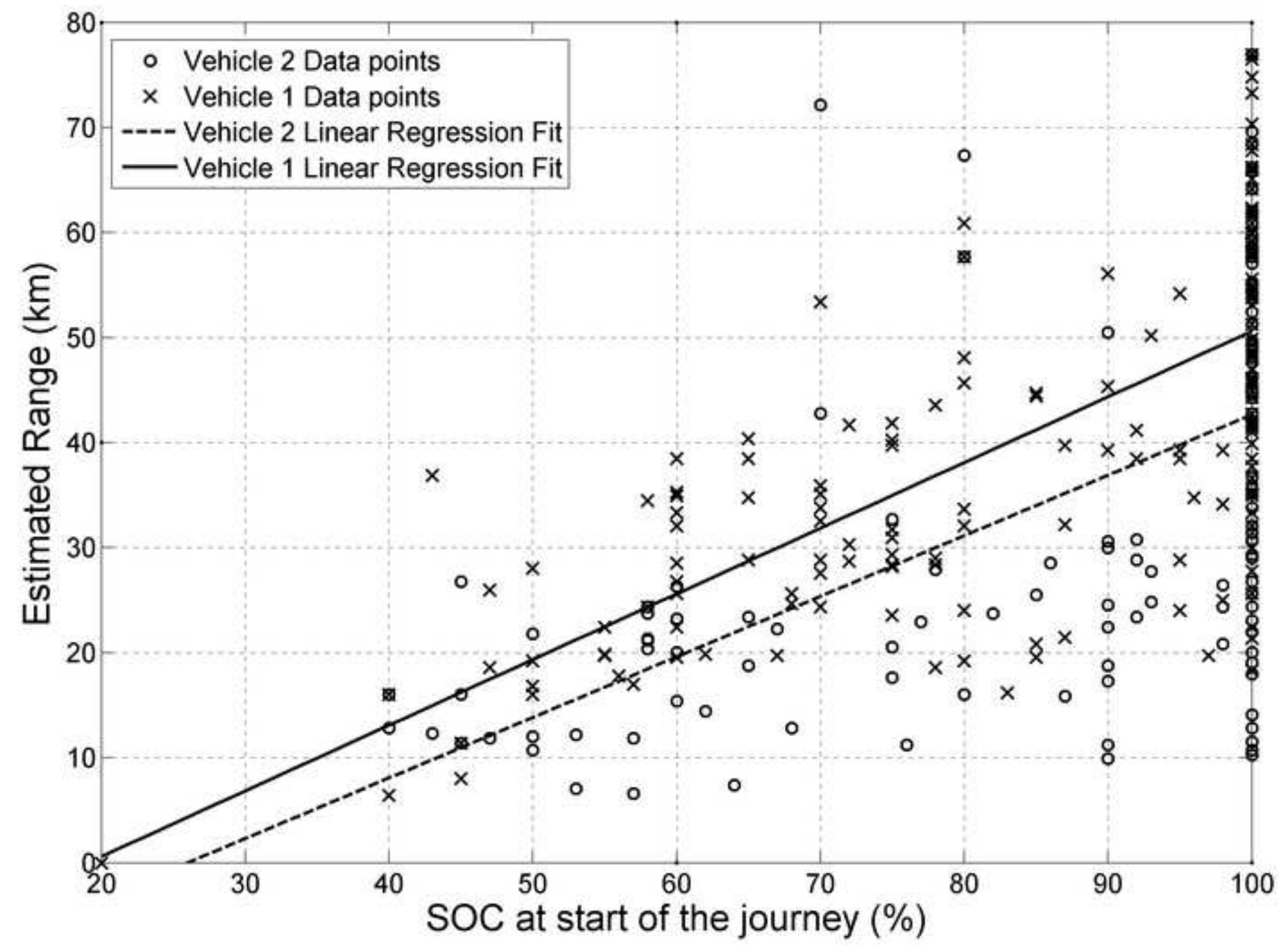


Click here to download high resolution image

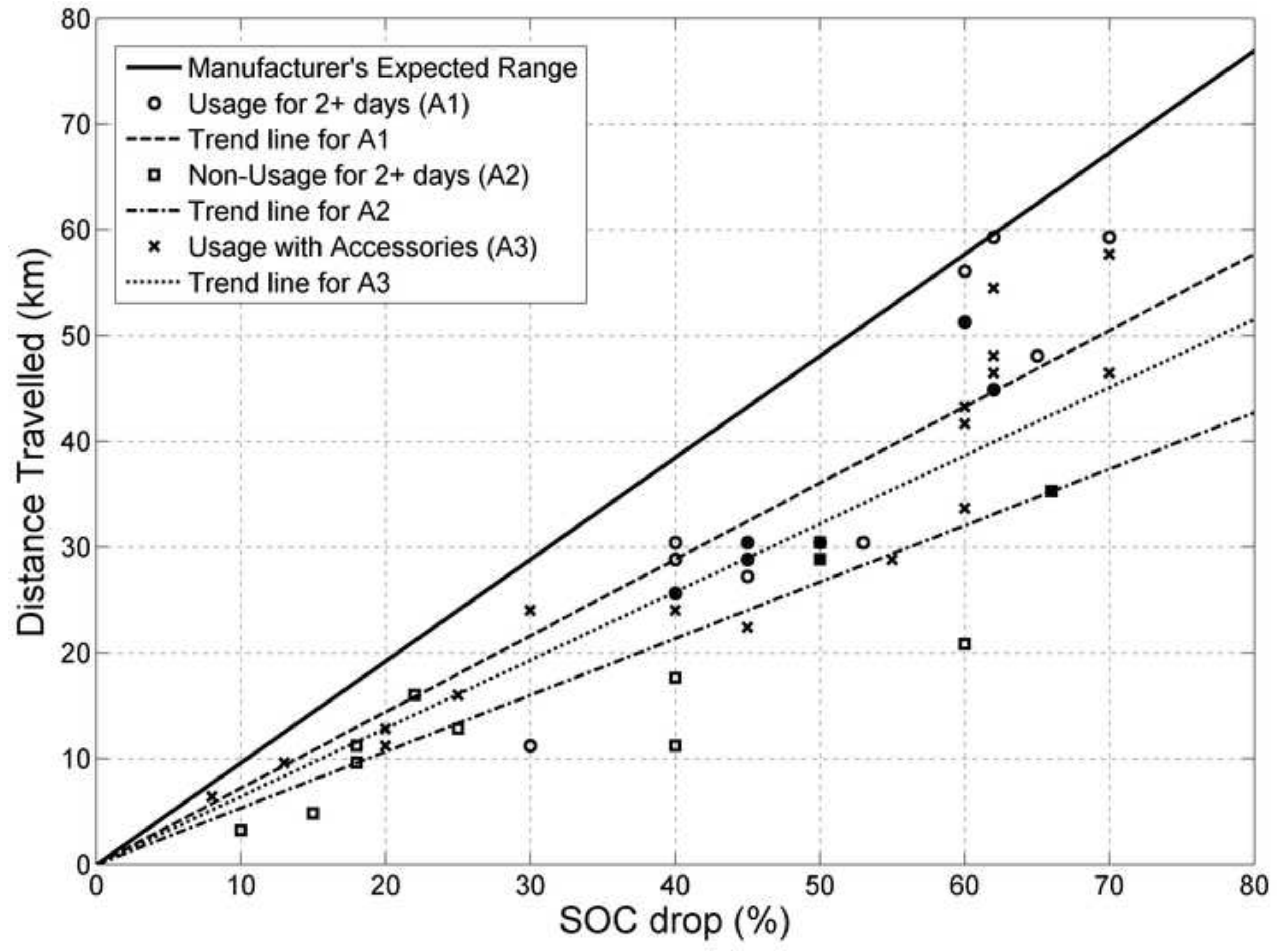




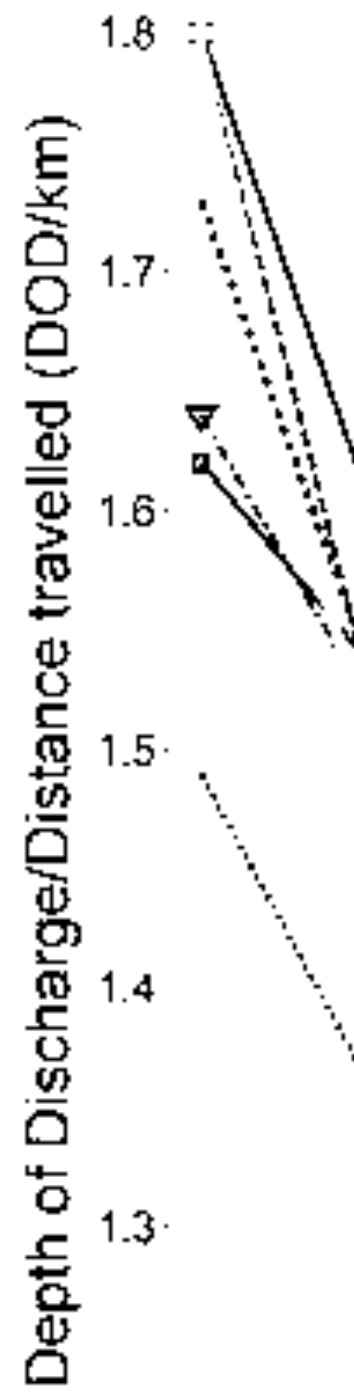

1.2

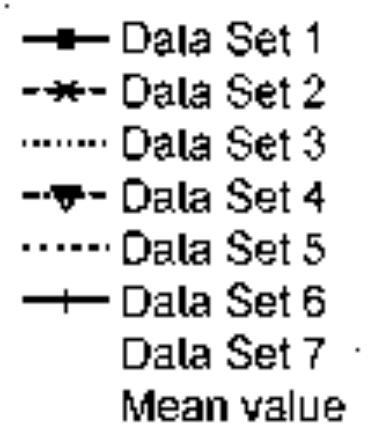

$\rightarrow$ Dalá Set 1

....... Dala Set 3

-p- Dala Set 4

(..... Dala Set 5 Dala Set 7

Mean value

\section{Day 1}

Day 2

Day 3

Day 4

Day 5

Day 6

Day 7 


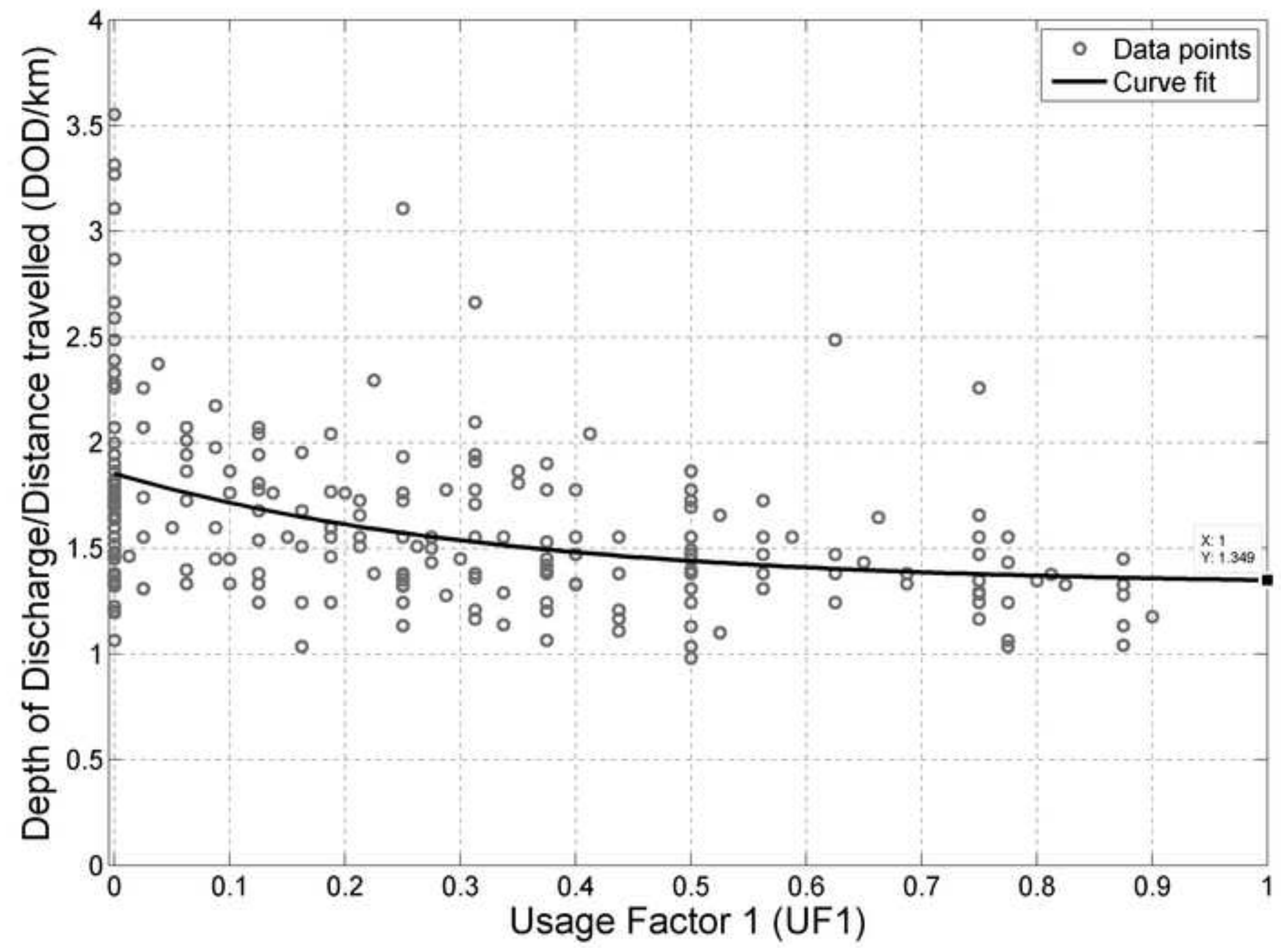




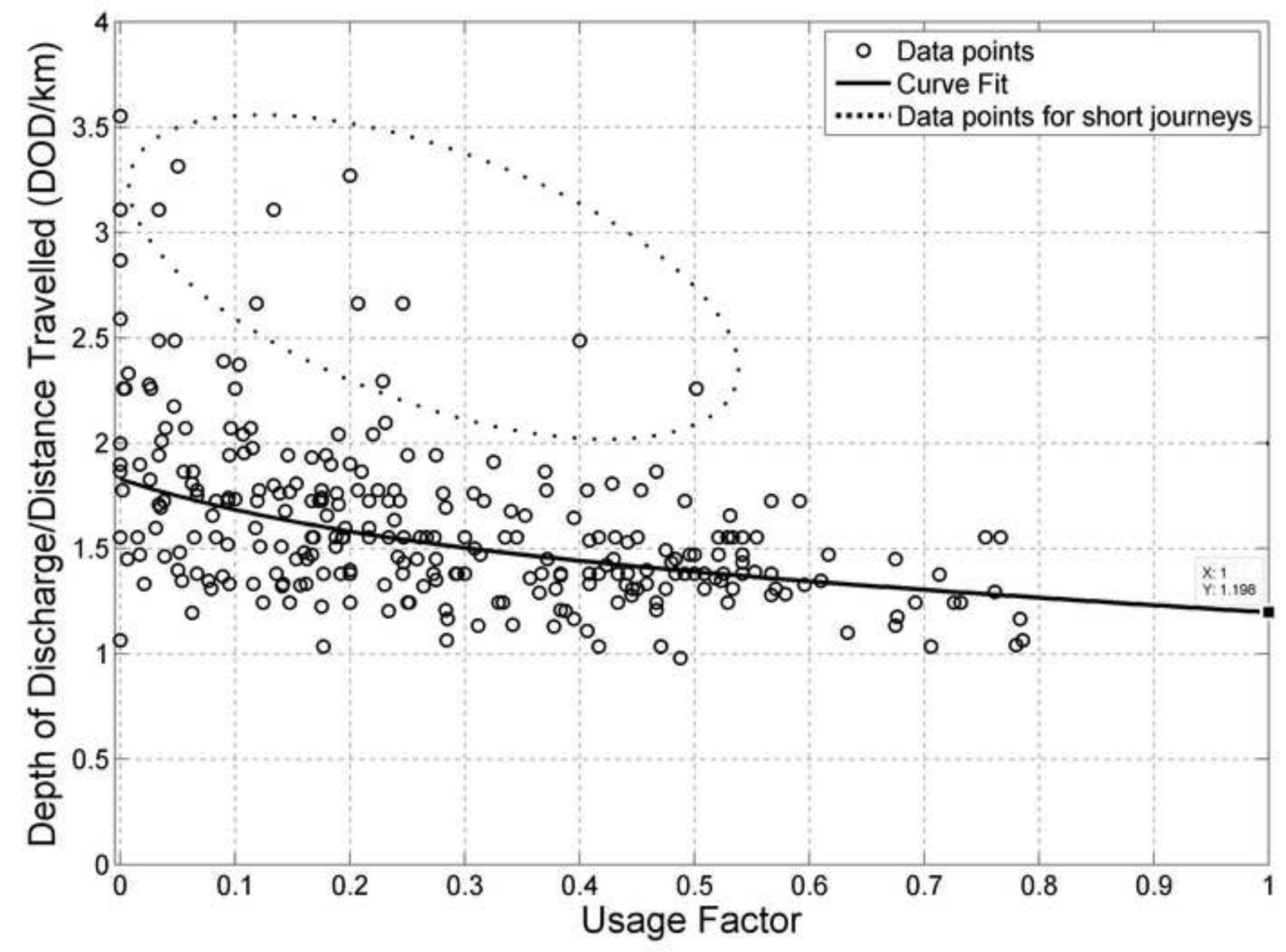




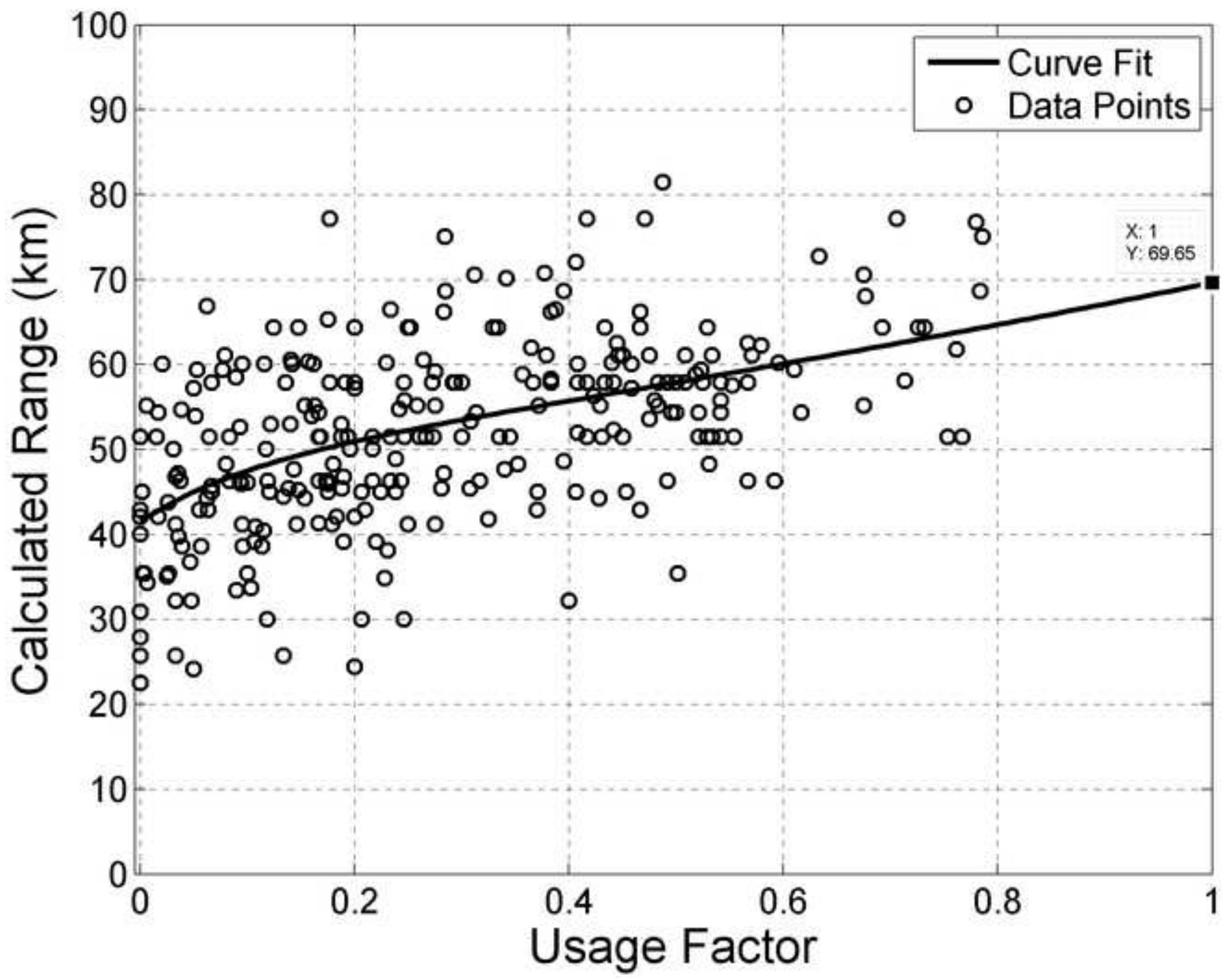


Click here to download high resolution image

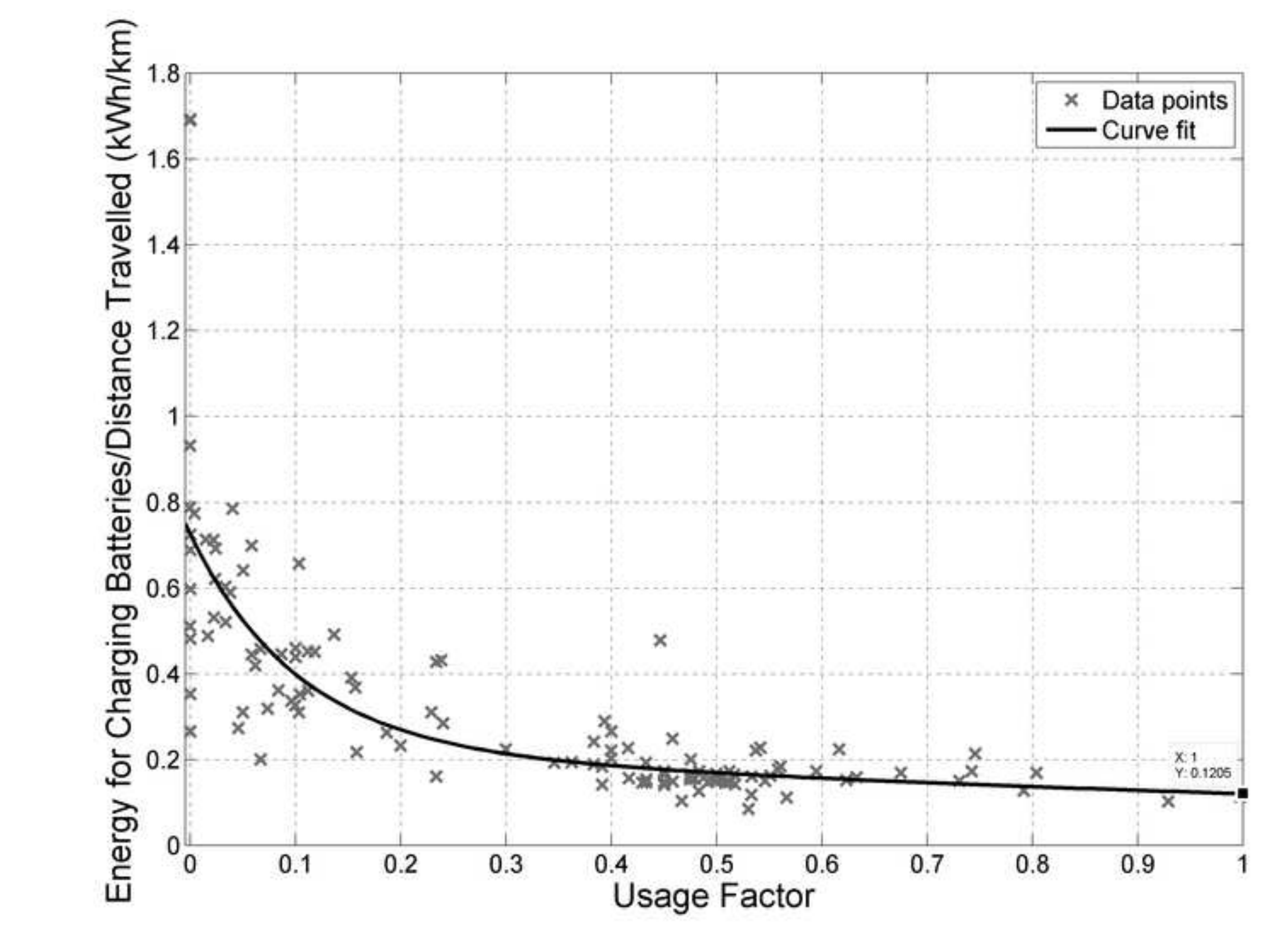

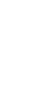

(
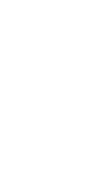


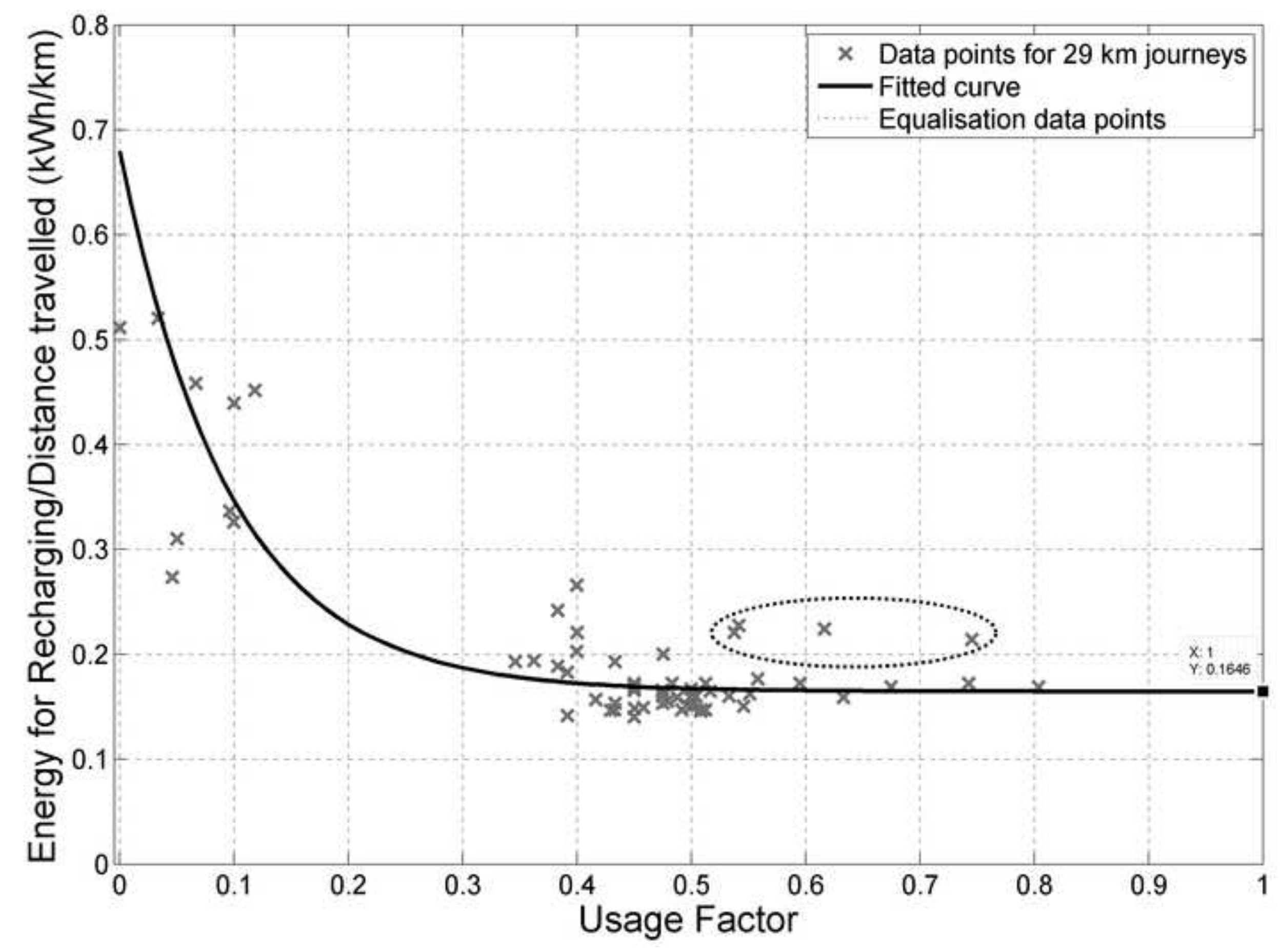




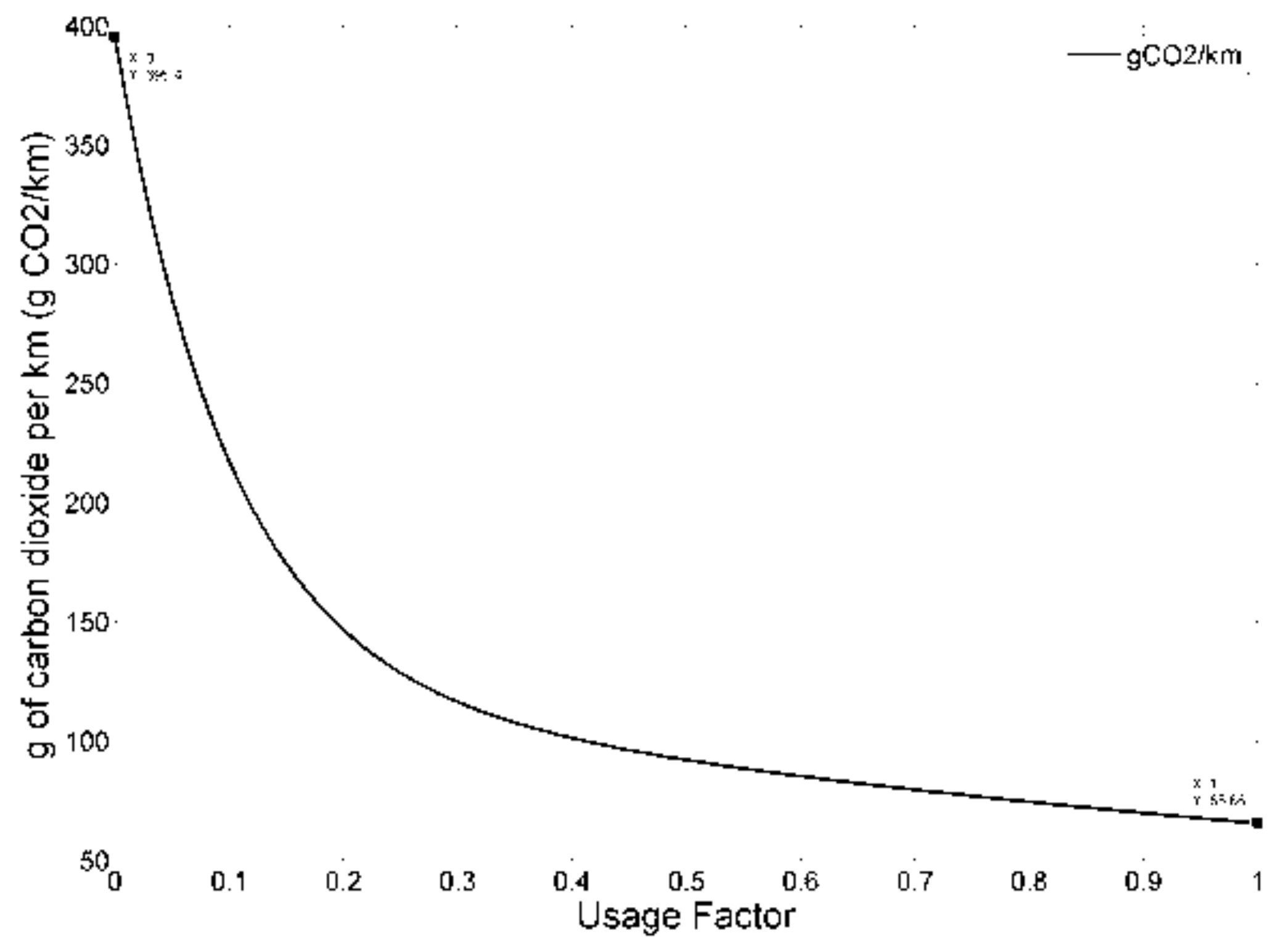


Table 1 - Vehicle specifications

\begin{tabular}{|c|c|c|}
\hline Attribute & $\begin{array}{l}\text { Reva G-Wiz AC version } \\
\text { (Vehicle 1) }\end{array}$ & $\begin{array}{c}\text { Reva G-Wiz I } \\
\text { (Vehicle 2) }\end{array}$ \\
\hline Battery & $\begin{array}{l}8 \times 6 \text { V Lead Acid Batteries } \\
\text { connected in series, } 200 \mathrm{Ah}\end{array}$ & $\begin{array}{l}8 \times 6 \mathrm{~V} \text { Lead Acid Batteries } \\
\text { connected in series, } 200 \mathrm{Ah}\end{array}$ \\
\hline Motor & $\begin{array}{l}\text { AC induction motor, } 3 \\
\text { phase, } 6 \mathrm{~kW} \text { continuous }\end{array}$ & $\begin{array}{l}\text { AC induction motor, } 3 \text { phase, } 6 \\
\mathrm{~kW} \text { continuous }\end{array}$ \\
\hline Charging time & $\begin{array}{l}8 \text { hours } 100 \%, 2.5 \text { hours } \\
80 \%\end{array}$ & 8 hours $100 \%, 2.5$ hours $80 \%$ \\
\hline Brakes & $\begin{array}{l}\text { Drums and regenerative } \\
\text { braking }\end{array}$ & $\begin{array}{l}\text { Front discs, rear drums and } \\
\text { regenerative braking }\end{array}$ \\
\hline Weight & $\begin{array}{l}665 \mathrm{~kg} \text { including batteries, } \\
400 \mathrm{~kg} \text { excluding batteries }\end{array}$ & $\begin{array}{l}665 \mathrm{~kg} \text { including batteries, } 400 \\
\text { kg excluding batteries }\end{array}$ \\
\hline $\begin{array}{l}\text { Manufacturer's } \\
\text { quoted maximum } \\
\text { speed }(\mathrm{km} / \mathrm{h})\end{array}$ & 72 & 80 \\
\hline $\begin{array}{l}\text { Manufacturer's } \\
\text { quoted range }(\mathrm{km})\end{array}$ & 77 & 77 \\
\hline $\begin{array}{l}\text { Lotus assisted } \\
\text { safety pack - crash } \\
\text { tested }\end{array}$ & No & Yes \\
\hline
\end{tabular}


Table 1 - Example for Usage factor calculation

\begin{tabular}{|c|r|r|c|c|c|c|c|}
\hline Date & $\begin{array}{c}\text { SOC } \\
\text { at } \\
\text { Start }\end{array}$ & $\begin{array}{c}\text { SOC } \\
\text { at } \\
\text { End }\end{array}$ & $\begin{array}{c}\text { Distance } \\
\text { travelled } \\
(\mathbf{k m})\end{array}$ & DOD & $\begin{array}{c}\text { Weighting } \\
\text { coefficient }\end{array}$ & day & Usage \\
number $\boldsymbol{x}$ & Factor \\
\hline $03 / 11 / 07$ & $0 \%$ & $0 \%$ & 0.0 & 0 & 10.00 & 4 & \\
\hline $04 / 11 / 07$ & $100 \%$ & $40 \%$ & 28.9 & 60 & 5.00 & 3 & \\
\hline $05 / 11 / 07$ & $100 \%$ & $90 \%$ & 16.0 & 10 & 2.50 & 2 & \\
\hline $06 / 11 / 07$ & $100 \%$ & $70 \%$ & 19.2 & 30 & 1.25 & 1 & \\
\hline $07 / 11 / 07$ & & & & & & & 0.3333 \\
\hline
\end{tabular}


Table 1 - Quality of fit for various usage factors

\begin{tabular}{|l|c|c|c|}
\hline Data & SSE & $\mathrm{R}^{2}$ & RMSE \\
\hline DOD/km with UF & 21.15 & 0.5563 & 0.2739 \\
\hline DOD/km with UF & & & \\
\hline DOD/km with $\mathrm{UF}_{5}$ & 21.16 & 0.5562 & 0.2739 \\
\hline DOD/km with $\mathrm{UF}_{6}$ & 20.83 & 0.5558 & 0.2728 \\
\hline DOD/km with $\mathrm{UF}_{15}$ & 21.69 & 0.5347 & 0.2808 \\
\hline
\end{tabular}

